\title{
Benveniste controversy rages on in the French press
}

\section{Paris}

THE publication in Nature $\mathbf{3 3 3}, 816-818$; 1988) of Jacques Benveniste's claims for the continued biological activity of solutions no longer containing molecules of the active constituent provoked a flurry of excitement in the French press. The absence of effect subsequently found by Nature's own team of investigators (see Nature 334, 287-291; 1988) has, with almost poetic irony, created at least as much of a press reaction as the original claim. Meanwhile, if Benveniste's own institute, INSERM (Institut National de la Santé et de la Recherche Médicale) is embarrassed by the controversy, Laboratoires Boiron, the manufacturers of homoeopathic products which co-sponsored Benveniste's work, have been busy on the stock market.

Benveniste is no stranger to the French press. While Nature's editors were still considering whether to publish the research, the French newspaper Le Monde, in its issue dated 29-30 May 1988, interviewed Benveniste after he had presented his findings to a national homoeopathy conference in Strasbourg. Admitting the results could not be explained by current theory, Benveniste threw down the gauntlet, telling Le Monde that "only the publication of our work in an undisputed international journal will enable us to advance".

When the paper was published, it caused reactions in the French media ranging from 'incredible-but-true' to fantastic speculations. While Le Figaro has maintained a reserve throughout, balancing Benveniste's comments with the respectful disbelief of Nobel prizewinner Jean-Marie Lehn, Le Monde and Libération have joined the mud-slinging. Between the publication of Benveniste's paper and last week, Le Monde, with an opening sentence "magic to the rescue of reason", demoted Nature with the phrase "until now one of the most prestigious [scientific journals] in the world".

Libération, which pre-empted Nature's publication of its report by giving Benveniste's own account of the inquiry, also felt, in a three-page follow-up on July 29, that Nature "has perhaps more to lose than Benveniste", saying Nature's editors were "the most two-faced of the lot".

If the choice of James Randi and Walter Stewart as arbiters has scandalized Benveniste, the attitude of the INSERM directorate has also wounded him. In an initial communiqué, dated 29 June, INSERM refused to express an opinion on the results. "Every real discovery inevitably incites temporary incredulity, using its customary methods of evaluation, where scientific controversy has its place, to sort out what, in the final account, turns out to be no more than illusion, from that which constitutes a real advance in knowledge."

When Nature subsequently published its rebuttal, INSERM issued another statement, again saying it would not enter the debate. "The institute repeats that all of its laboratories are themselves responsible for their choice of research themes and are, every four years, subjected to an in-depth scientific evaluation of their activities. Unit 200 of INSERM, directed by Dr Benveniste, will be subjected to its next regular examination in Spring 1989. It is within this framework that it will fall to Dr Benveniste's peers to make their judgement on the entirety of the work of the group, at a time when we hope that the understandable passions released or maintained by the to-and-fro of the two successive publications in Nature will have been calmed, leaving room for the indispensable serenity of scientific judgements in the long run."

In the 29 July issue of Libération, Ben- veniste complained that INSERM had, effectively, thrown him to the wolves. "Nature sends a magician to check my research and INSERM doesn't even protest. It's the limit!"

While the scientific controversy continues, the industrial co-sponsors of Benveniste's research, Laboratoires Boiron, have been making sure they benefit from any renewed interest in homoeopathy. Boiron, already a 51 per cent shareholder in another major manufacturer of homoeopathic medicines, Laboratoires Homéopathiques de France (LHF), last week decided to buy up the remaining shares. In Le Monde of $29 \mathrm{July}$, a Boiron spokesman is reported as saying that "Nature is trying to cover itself... and must be under great pressure to attenuate the impact of the recent publication. One must be aware that the scientific community is faced with a reality that has 'put the wind up it' and that it will react in a variety of ways".

The last word (so far) goes to the monthly popular science magazine, Science et Vie, which claims to have proved that Benveniste's results demonstrate only the discoloration (achromasie) of the toluidine stain, not degranulation of basophils, also wondering: if water has a 'memory', how can it ever be 'pure'?

Peter Coles

\section{Restructuring of UK research could be misguided}

\section{London}

THE academic research system in Britain is being restructured in order to get the best value for money at a time when government policy is constricting public funding. But the current restructuring policy which grades individual department and not whole institutions may be inappropriate, according to a study published last week by John Irvine of the Science Policy Research Unit at the University of Sussex. In his study of the performance of 13 technology-oriented universities, he finds that research excellence in a broad range of fields is concentrated in a small number of institutions.

His findings seem to support the view of the government advisers on science policy, the Advisory Board for the Research Councils (ABRC) that research resources should be concentrated in centres of excellence. The ABRC proposed last year that higher education institutions should be divided into three types: research-based, mixed research and teaching, and teaching based. But that proposal was severely criticized by the academic community.

The University Grants Committee, adviser to the government on the distribution of grants, then proceeded with its policy of restructuring universities on a subject-by-subject basis, with a view to making recommendations for support to individual departments regardless of the overall performance of host institutions. A review of the Earth sciences was completed this year and that too was criticized by academics. Reviews of chemistry and physics are now under way and preliminary reports are due soon.

Irvine based his study on comparisons of science citations and the influence of the journals in which the citations appear. Of the institutions studied, Irvine says preliminary results show strong indications of concentration of research excellence, with three universities being in the top five for chemistry, engineering, physics, biological sciences, mathematics and Earth and space sciences.

The higher classified universities receive a proportionately greater amount of research grants and a higher level of contracts and grants from companies, says Irvine. And he finds a strong linkage between output of high quality basic scientific and engineering research and its perceived utility to industry.

Irvine acknowledges that bibliometric studies of research performance are subject to limitations, and says further research is necessary before reliable conclusions on which to base policy decisions can be drawn.

Christine McGourty 